\title{
Kaplı ve Kapsız Şeker Pancarı Tohumlarının Çimlenme, Çıkış ve Verim Bakımından İncelenmesi
}

\author{
*Engin Gökhan KULAN Mehmet Demir KAYA
}

Eskişehir Osmangazi Üniversitesi, Ziraat Fakültesi, Tarla Bitkileri Bölümü, Eskişehir

*Sorumlu yazar e-mail (Corresponding author e-mail): egk_88@hotmail.com

\section{Öz}

Bu çalışma Eskişehir koşullarında bazı şeker pancarı çeşitlerinin kaplı ve kapsız tohumlarının çimlenme, çıkış, verim ve polar şeker oranı bakımından performanslarının değerlendirilmesi amacıyla 2014 yılında tarla ve laboratuvar denemeleri olarak yürütülmüştür. Araştırmada Eldorado, Coyote, Stine ve Giraf şeker pancarı çeşitlerine ait kaplı ve kapsız tohumları kullanıımışıı. Laboratuvar denemelerinde çimlenme yüzdesi, ortalama çimlenme süresi, çıkış yüzdesi ve ortalama çıkış süresi; tarla denemelerinde ise tarla çıkı̧ (\%), kök-gövde boyu $(\mathrm{cm})$, kök-gövde çapı $(\mathrm{cm})$, kök-gövde ağılığı (g/bitki), kök-gövde verimi $(\mathrm{kg} / \mathrm{da})$ ve polar şeker oranı (\%) özellikleri incelenmiştir. Araştırma sonuçlarına göre, kaplı ve kapsız tohumların çimlenme yüzdesi, ortalama çimlenme süresi, çıkış yüzdesi ve süresi bakımından önemli farklııklar belirlenmiştir. Kapsız tohumların çimlenme ve çıkış yüzdesi kaplı tohumlara göre daha yüksek bulunurken, daha kısa çimlenme ve çıkış süresi belirlenmiştir. Tarla denemelerinde incelenen özellikler arasında kaplı ve kapsız tohumlar arasında önemli bir farklılık belirlenmemiştir. Dekara verim bakımından sadece Giraf çeşidinin kaplı ve kapsız tohumlar arasında farklılık belirlenmiş, diğer çeşitlerde belirlenen farklılıklar önemsiz bulunmuştur. Sonuç olarak, çeşitlerin kaplı ve kapsız tohumları çimlenme ve çıkış özellikleri farklııık gösterse de, verim ve polar şeker oranı bakımından bir farkııı̆ı̆ın bulunmadığı söylenebilir.

Anahtar Kelimeler: Beta vulgaris L., tohum kaplama, çimlenme, çıkış, verim

\section{Investigation of Coated and Uncoated Seeds of Sugar Beet with Respect to Germination, Emergence and Yield}

\begin{abstract}
Field and laboratory experiments were conducted to determine the performance of the coated and uncoated seeds of sugar beet cultivars with respect to germination, emergence, yield and polar sugar content under Eskişehir Conditions in 2014. Coated and uncoated seeds of sugar beet cvs. Eldorado, Coyote, Stine and Giraf were used in the study. Germination percentage, mean germination time, emergence percentage and mean emergence time in laboratory experiment and field emergence percentage, root length, root diameter, root weight, root yield and polar sugar content were measured. The results showed that a significant difference between coated and uncoated seeds for germination and emergence performance was found. Higher germination and emergence percentage were detected in the uncoated seeds while no significant variation was found in field experiments. Differences between coated and uncoated seeds of only cv. Giraf were significant in root yield. It was concluded that any significant advantage between seeds types for root yield and polar sugar content was not determined in field experiments while the superiority of uncoated seeds in laboratory experiment was detected for germination and emergence.
\end{abstract}

Keywords: Beta vulgaris L., seed coating, germination, emergence, root yield

\section{Giriş}

TT arımı ve sanayisi ile ülkemizin en önemli bitkilerinden birisi şeker pancarıdır. Başta şeker üretimi ile insan beslenmesinde olmak üzere, küspe, baş ve yaprakları ile hayvan beslemede ve alkol üretimi ile çeşitli sanayi alanlarına önemli katkıları bulunmaktadır. 2014 yılı verilerine göre 288 bin ha ekim alanında 16.5 milyon ton üretimi olan şeker pancarının dekara ortalama verimi ise $5765 \mathrm{~kg}$ olarak gerçekleşmiştir. Ekim alanlarımızın yaklaşık \%70'ini Orta Anadolu ve Geçit bölgeleri karşılamaktadır (Anonim 2015a). 
Ülkemizde tescilli şeker pancarı çeşit sayısı 95 civarındadır (Anonim 2015b). Bu çeşitlere ait kaplı ve kapsız (çıplak) tohumlar üretilerek çiftçilere dağıtılmaktadır. Kaplı tohumlar özellikle hassas ekim makinalarıyla ekime olanak vermesi, birçok fungusit ve insektisitin uygulanmasına imkân sağlaması ve bazı bitki besin maddelerinin kaplamayla birlikte uygulanabilmesi nedeniyle tercih edilmektedir (Arıoğlu 2000; McQuilken et al. 2007). Ayrıca kaplama malzemelerinin içerisine çimlenmeyi ve fide gelişimini teşvik ediciler de karıştıılarak daha hızlı çimlenme, çıkış ve fide gelişimi elde edilebilmektedir (Taylor et al. 1998). Bununla birlikte, kaplama işlemi tohumluğun maliyetini arttırmakta ve kapsız tohumlara oranla iki kat fiyatla pazarda satılabilmektedir. Bu çalışma, şeker pancarında kaplı ve kapsız (çıplak) tohumların çimlenme, çıkış, verim ve polar şeker oranı bakımından performanslarını test etmek amacıyla yürütülmüştür.

\section{Materyal ve Yöntem}

Bu araştırma 2014 yılında Eskişehir Osmangazi Üniversitesi Ziraat Fakültesi Tarla Bitkileri Bölümü'nde laboratuvar ve tarla denemeleri olarak yürütülmüştür. Çalışmada Beta Ziraat ve Tic. A.Ş.'den temin edilen Eldorado, Coyote, Stine ve Giraf şeker pancarı çeşitlerine ait kaplı ve kapsız tohumlar kullanılmıştır.

Çimlendirme denemeleri kurutma kâğıtları arasında ve $25 \pm 1{ }^{\circ} \mathrm{C}$ ' de tamamen karanlık çimlendirme dolabında, 4 tekerrürlü ve her tekerrürde 50 adet tohum olacak şekilde yürütülmüştür. Her kurutma kağıdı için $8 \mathrm{ml}$ distile su eklendikten sonra buharlaşmayı engellemek amacıyla ağzı kilitli plastik torbalara konulmuştur. Tohumlar her gün sayılmış ve 1 $\mathrm{mm}$ kökçük uzunluğuna sahip tohumlar çimlenmiş kabul edilmiştir. 14. günde toplam çimlenen tohumlar sayılarak çimlenme yüzdesi (\%) belirlenmiştir. Çimlenme hızını belirlemek amacıyla ortalama çimlenme süresi Anonim (2003)'e göre hesap edilmiştir. Çıkış denemeleri $30 \times 40 \times 7 \mathrm{~cm}$ boyutlarındaki kaplarda torf kullanılarak, 4 tekerrürlü ve her tekerrürde 50 adet tohum olacak şekilde yürütülmüştür. Tohumlar $2 \mathrm{~cm}$ derinliğe ekilmiş, 16 saat gündüz / 8 saat gece ve $25 / 20{ }^{\circ} \mathrm{C}$ sıcaklıkta $\% 60$ nispi neme ayarlı bitki büyütme kabininde bekletilmiştir. Çıkış yapan bitkiler her gün sayılmış ve 14. gün sonunda çıkan bitkiler sayılarak çıkış yüzdesi (\%) hesaplanmıştır.

Kotiledon yaprakların toprak yüzeyine çıkması çıkış kriteri olarak değerlendirilmiştir.

Tarla denemelerinin yürütüldüğü alanının farklı yerlerinden alınan toprak örneklerinde toprak yapısı ve toprağın bazı kimyasal özellikleri bakımından yapılan analiz sonuçlarına göre, deneme alanı toprağı killi-tınlı yapıya sahip olup, hafif alkali, orta derecede kireçli, tuzsuz, fosfor ve organik maddece düşük, potasyumca yeterli olduğu belirlenmiştir. Deneme alanının drenajı iyi ve taban suyu problemi bulunmamaktadır.

Araştırmanın yürütüldüğü 2014 yılına ait aylık ortalama sıcaklık $\left({ }^{\circ} \mathrm{C}\right)$, nispi nem (\%) ve toplam yağış $(\mathrm{mm})$ değerleri ile bunların uzun yıllar ortalaması Çizelge 1' de gösterilmiştir. Yağış bakımından uzun yıllar ortalamasına yakın değerler görülmesine rağmen vejetasyon döneminde toplam $273.1 \mathrm{~mm}$ yağış alınmıştır.

Çizelge 1. Deneme alanına ait bazı iklim verileri

Table 1. Climate data from experimental site

\begin{tabular}{|c|c|c|c|c|c|c|}
\hline \multirow[b]{2}{*}{ Aylar } & \multicolumn{3}{|c|}{ Uzun yıllar (1970- 2013) } & \multicolumn{3}{|c|}{2014} \\
\hline & Yağış (mm) & $\begin{array}{c}\text { Sicaklık } \\
\left({ }^{\circ} \mathrm{C}\right)\end{array}$ & Nem (\%) & $\begin{array}{l}\text { Yağış } \\
(\mathrm{mm})\end{array}$ & Sicaklık $\left({ }^{\circ} \mathrm{C}\right)$ & Nem $(\%)$ \\
\hline Ocak & 30.6 & -0.2 & 75.2 & 13.6 & 3.0 & 84.1 \\
\hline Şubat & 26.1 & 0.9 & 70.6 & 5.8 & 4.2 & 68.2 \\
\hline Mart & 27.6 & 4.9 & 64.2 & 23.1 & 6.3 & 68.4 \\
\hline Nisan & 43.1 & 9.6 & 62.7 & 15.2 & 11.5 & 62.7 \\
\hline Mayıs & 40.0 & 14.9 & 59.5 & 27.2 & 15.1 & 66.2 \\
\hline Haziran & 23.7 & 19.1 & 55.2 & 70.6 & 18.5 & 66.9 \\
\hline Temmuz & 13.1 & 22.1 & 51.9 & 7.5 & 22.6 & 58.6 \\
\hline Ağustos & 9.2 & 21.8 & 53.6 & 27.0 & 23.0 & 59.8 \\
\hline Eylül & 18.1 & 16.7 & 58.4 & 82.7 & 17.4 & 70.7 \\
\hline Ekim & 32.8 & 11.7 & 64.7 & 42.9 & 12.2 & 78.9 \\
\hline Kasım & 34.0 & 5.6 & 70.5 & 15.6 & 6.3 & 80.9 \\
\hline Aralık & 40.5 & 1.7 & 75.9 & 26.8 & 5.0 & 87.8 \\
\hline Toplam & 338.8 & & - & 358.0 & - & - \\
\hline Ortalama & & 10.7 & 71.1 & - & 12.1 & 62.3 \\
\hline
\end{tabular}


Bu değer vejetasyon döneminin uzun yıllar ortalaması olan $137.0 \mathrm{~mm}$ 'nin oldukça üzerinde gerçekleşmiştir. Yağışın fazla olduğu aylarda ortalama sıcaklığın daha düşük gerçekleşmesine neden olmuştur.

Tarla denemeleri tesadüf bloklarında bölünmüş parseller deneme desenine göre 4 tekerrürlü olarak kurulmuştur. Ekim, 11.04.2014 tarihinde $4.0 \times 1.8 \mathrm{~m}=7.2 \mathrm{~m}^{2}$ lik parsellere 4 sıra olarak $45 \times 25 \mathrm{~cm}$ bitki sıklığı ile yapılmıştır. Ekimden önce dekara $25 \mathrm{~kg}$ Diamonyum fosfat (DAP 18-46-0) gübresi uygulanmıştır. Çıkış tamamlandıktan sonra bir kez el çapası yapılmıştır. Üst gübreleme olarak $20 \mathrm{~kg} / \mathrm{da}$ amonyum sülfat $(\% 21 \quad \mathrm{~N})$ gübresi ikinci sulamadan önce verilmiştir. Sulama 15 haziran15 eylül tarihleri arasında yağmurlama sulama yöntemiyle gerçekleştirilmiştir. Yağmurlama başlıkları $15 \times 10 \mathrm{~m}$ tertip düzeninde yerleştirilmiş ve saatte 2 ton su veren yağmurlama başlıkları kullanılmıştır. Etkili kök derinliği $90 \mathrm{~cm}$ olacak şekilde alınmıştır. Sulama aralığı 18 gün, sulama sayısı 6 olacak şekilde sulama uygulanmıştır. Tüm yetiştirme periyodu boyunca $500 \mathrm{~mm}$ sulama suyu uygulanmıştır. Hasat 18.10.2014 tarihinde elle yapılmıştır. Parsellerde sökülen bitkilerde ölçümler tamamlandıktan sonra ham şeker oranlarının belirlenmesi Eskişehir Şeker Fabrikası'nda polarimetre yardımıyla belirlenmiştir.
Tarla denemeleri sonunda elde edilen veriler tesadüf bloklarında bölünmüş parseller, laboratuvar denemeleri sonunda elde edilen veriler ise tesadüf parsellerinde faktöriyel deneme desenine göre varyans analizi yapılmıştır. Uygulamalar arasındaki farkların önem düzeylerini belirleyebilmek amacıyla Duncan Çoklu Karşılaştırma Testi uygulanmıştır. Tohum tipleri arasında belirlenen farklılıkların önemlilik durumları t-testi ile belirlenmiştir (Düzgüneş ve ark. 1987). Tüm istatistiksel hesaplamalar bilgisayarda MSTATC (Michigan State University, version 2.10) paket programı kullanılarak yapılmıştır.

\section{Bulgular ve Tartışma}

Dört şeker pancarı çeşidine ait kaplı ve kapsız tohumların çimlenme ve çıkış özelliklerine ilişkin ortalamalar ve farklılık gruplandırmaları Çizelge 2'de gösterilmiştir. İncelenen tüm özelliklerde çeşit $x$ tohum tipi interaksiyonu istatistiksel olarak önemli bulunmuştur. Tüm çeşitlerde kapsız tohumlar kaplı tohumlardan daha yüksek çimlenme yüzdesi vermiştir. En yüksek çimlenme Giraf çeşidinin kapsız tohumlarından \%85.0 ile elde edilirken, en düşük çimlenme \%11.0 ile Stine çeşidinin kaplı tohumlarında belirlenmiştir (Çizelge 2). Çeşitlerin kapsız tohumlarının çimlenme yüzdeleri arasındaki farklııılar da önemli bulunmuştur. $\mathrm{Bu}$

Çizelge 2. Bazı şekerpancarı çeşitlerine ait kaplı ve kapsız tohumların çimlenme ve çıkış özellikleri

Table 2. Germination and emergence performances of coated and uncoated seeds of some sugar beet cultivars

\begin{tabular}{|c|c|c|c|c|c|}
\hline \multicolumn{2}{|c|}{ Faktör } & $\begin{array}{c}\text { Çimlenme } \\
(\%)\end{array}$ & $\begin{array}{l}\text { Çimlenme süresi } \\
\text { (gün) }\end{array}$ & $\begin{array}{l}\text { Lab. çıkış } \\
(\%)\end{array}$ & $\begin{array}{c}\text { Çıkış süresi } \\
\text { (gün) }\end{array}$ \\
\hline \multicolumn{6}{|c|}{ Çeşit } \\
\hline \multicolumn{2}{|c|}{$\begin{array}{c}\text { Eldorado } \\
\text { Coyote } \\
\text { Stine } \\
\text { Giraf }\end{array}$} & $\begin{array}{l}37.3^{\mathrm{bc} 2} \\
33.8^{\mathrm{c} 2} \\
41.8^{\mathrm{b} 2} \\
75.8^{\mathrm{a} 1}\end{array}$ & $\begin{array}{l}7.91^{\mathrm{a} 1} \\
7.25^{\mathrm{a} 1} \\
7.66^{\mathrm{a} 1} \\
5.23^{\mathrm{b} 2}\end{array}$ & $\begin{array}{l}66.8^{\mathrm{b} 2} \\
60.0^{\mathrm{b} 2} \\
68.0^{\mathrm{b} 2} \\
87.5^{\mathrm{a} 1}\end{array}$ & $\begin{array}{c}5.87^{\mathrm{b} 2^{*}} \\
5.40^{\mathrm{c} 23} \\
6.72^{\mathrm{a} 1} \\
5.16^{\mathrm{c3}}\end{array}$ \\
\hline \multicolumn{6}{|c|}{ Tohum tipi } \\
\hline \multicolumn{2}{|c|}{$\begin{array}{c}\text { Kapsız } \\
\text { Kaplı }\end{array}$} & $\begin{array}{l}65.4^{\mathrm{a} 1} \\
28.9^{\mathrm{b} 2} \\
\end{array}$ & $\begin{array}{l}4.72^{\mathrm{a} 1} \\
9.30^{\mathrm{b} 2} \\
\end{array}$ & $\begin{array}{l}89.9^{\mathrm{a} 1} \\
51.3^{\mathrm{b} 2}\end{array}$ & $\begin{array}{l}5.03^{\mathrm{a} 1} \\
6.54^{\mathrm{b2}} \\
\end{array}$ \\
\hline \multicolumn{6}{|c|}{ Çeşit $\times$ tohum tipi } \\
\hline Eldorado & $\begin{array}{c}\text { Kapsız } \\
\text { Kaplı }\end{array}$ & $\begin{array}{l}54.0^{\mathrm{c} 34} \\
20.5^{\mathrm{db}}\end{array}$ & $\begin{array}{l}5.36^{\mathrm{c23}} \\
10.54^{\mathrm{a} 1}\end{array}$ & $\begin{array}{l}86.0^{\mathrm{ab} 12} \\
47.5^{\mathrm{c} 3}\end{array}$ & $\begin{array}{l}4.72^{\mathrm{d}} \\
7.01^{\mathrm{a}}\end{array}$ \\
\hline Coyote & $\begin{array}{c}\text { Kapsız } \\
\text { Kaplı }\end{array}$ & $\begin{array}{l}50.0^{\mathrm{c} 4} \\
17.5^{\mathrm{db}}\end{array}$ & $\begin{array}{l}4.42^{\mathrm{cd} 3} \\
10.08^{\mathrm{a} 1}\end{array}$ & $\begin{array}{l}89.5^{\mathrm{ab} 12} \\
30.5^{\mathrm{d}}\end{array}$ & $\begin{array}{l}4.55^{d} \\
6.24^{b}\end{array}$ \\
\hline Stine & $\begin{array}{c}\text { Kapsız } \\
\text { Kaplı }\end{array}$ & $\begin{array}{l}72.5^{\mathrm{b} 12} \\
11.0^{\mathrm{db}}\end{array}$ & $\begin{array}{l}5.18^{\mathrm{c} 23} \\
10.13^{\mathrm{a} 1}\end{array}$ & $\begin{array}{c}88.0^{\mathrm{ab} 12} \\
48.0^{\mathrm{c} 3}\end{array}$ & $\begin{array}{l}6.10^{\mathrm{bc}} \\
7.33^{\mathrm{a}}\end{array}$ \\
\hline Giraf & $\begin{array}{c}\text { Kapsız } \\
\text { Kaplı }\end{array}$ & $\begin{array}{l}85.0^{\mathrm{a} 1} \\
66.5^{\mathrm{b} 23}\end{array}$ & $\begin{array}{l}3.93^{\mathrm{d} 3} \\
6.54^{\mathrm{b} 2}\end{array}$ & $\begin{array}{l}96.0^{\mathrm{a} 1} \\
79.0^{\mathrm{b} 2}\end{array}$ & $\begin{array}{l}4.75^{\mathrm{d}} \\
5.58^{\mathrm{c}}\end{array}$ \\
\hline
\end{tabular}

*: Harfler \%5, rakamlar \%1 düzeyinde farklı grupları göstermektedir.

*: Letters and numbers stands for $\% 5$ and $\% 1$ levels of importance, respectively. 
duruma özellikle pancar tohumlarında bulunan çimlenme engelleyici maddelerin neden olduğu ve çeşitlere göre farklıık gösterdiği Duan and Burris (1997) tarafından bildirilmiştir. Battle and Whittington (1969) şeker pancarı tohumunda çimlenmeyi engelleyici maddeler olan ferulik, vanillik, p-kumarik ve $p$-hidroksibenzoik asitlerin tohumun perikarp kısmında bulunduğunu bildirmiştir. Bu çimlenmeyi engelleyici maddeler nedeniyle çimlenme yüzdeleri düşük bulunmuştur. Ayrıca çeşitlerin kapsız tohumlarının çimlenme yüzdeleri de birbirinden farklı olması, çimlenme engelleyici maddelerin genetik kaynaklı olabileceğinin de göstergesi olarak değerlendirilmiştir. Ortalama çimlenme süresi bakımından ise kapsız tohumların daha kısa sürede çimlendiği tespit edilmiştir. En kısa sürede çimlenen Giraf çeşidinin kapsız tohumları olmuştur. Laboratuvar çıkış yüzdesi de kapsız tohumlarda daha yüksek bulunmuştur. En yüksek çıkış yüzdesi \%96.0 ile Giraf çeşidinin kapsız tohumlarından elde edilmiştir. Benzer şekilde çıkış süresi kapsız tohumlarda daha kısa, kaplı tohumlarda daha uzun olmuştur. Çimlenme yüzdesindeki azalma çimlenme süresinin uzamasına neden olmuştur. Özellikle kaplı tohumlarda kaplama materyalinin su alıp şişmesi ve parçalanması uzun süre gerektirdiğinden, çimlenme süresi daha uzun bulunmuştur. Tarla denemeleri sonucunda incelenen şeker pancarı çeşitlerine ait kaplı ve kapsız tohumlarından elde edilen verim, verim öğeleri, polar şeker oranı ve çıkış değerleri incelendiğinde, kök-gövde ağırlığı, dekara kök-gövde verimi ve polar şeker oranı bakımından çeşit $\times$ tohum tipi interaksiyonu istatistiksel olarak önemli bulunmuştur. Kökgövde ağırlığı bakımından en yüksek değer Eldorado çeşidinin kaplı tohumlarından elde edilirken, en düşük değer Stine çeşidinin kapsız tohumlarında tespit edilmiştir (Çizelge 3). Sadece Eldorado çeşidinin kaplı ve kapsız tohum arasında kök-gövde ağırlığı bakımından istatistiksel farklılık belirlenmiştir. Dekara kökgövde verimi en yüksek $(9706 \mathrm{~kg} / \mathrm{da})$ Eldorado çeşidinin kaplı tohumlarından, en düşük (7245 $\mathrm{kg} / \mathrm{da}$ ) ise Giraf çeşidinin kaplı tohumlarından elde edilmiştir.

Kaplı ve kapsız tohumlar arasında verim bakımından en büyük fark Giraf çeşidinde tespit edilmiştir. Polar şeker oranı bakımından Coyote, Stine ve Giraf çeşitlerinin kaplı ve kapsız tohumları arasında önemli bir farklılık belirlenmezken, Eldorado çeşidinde bu farklılık önemli bulunmuştur. Eldorado çeşidinin kapsız tohumlarında polar şeker oranı \%17.24 iken, kaplı tohumlarında \%15.07 olarak tespit edilmiştir. Çeşitler ve kullanılan tohum tipleri arasında kök-gövde boyu, kök-gövde çapı ve çıkış oranı bakımından önemli farklılıklar belirlenmemiştir. Kök-gövde boyu 21.53-25.80 cm, kök-gövde çapı 10.63-11.83 cm, çıkış oranı ise \%83.33-89.22 arasında değişim göstermiştir.

Çizelge 3. Bazı şekerpancarı çeşitlerine ait kaplı ve kapsız tohumların verim ve verim öğeleri

Table 3. Yield and some yield components of coated and uncoated seeds of some sugar beet cultivars

\begin{tabular}{|c|c|c|c|c|c|c|c|}
\hline \multicolumn{2}{|c|}{ Faktör } & $\begin{array}{l}\text { Kök ağırlığı } \\
\text { (g/bitki) }\end{array}$ & $\begin{array}{l}\text { Kök verimi } \\
\text { (kg/da) }\end{array}$ & $\begin{array}{c}\text { Ham } \\
\text { şeker } \\
\text { oranı (\%) } \\
\end{array}$ & $\begin{array}{l}\text { Kök boyu } \\
(\mathrm{cm})\end{array}$ & $\begin{array}{c}\text { Kök çapı } \\
(\mathrm{cm})\end{array}$ & $\begin{array}{c}\text { Çıkış } \\
(\%)\end{array}$ \\
\hline \multicolumn{8}{|c|}{ Çeşit } \\
\hline \multicolumn{2}{|c|}{ Eldorado } & 1173 & 9210 & 16.16 & 24.17 & 11.60 & 86.27 \\
\hline \multicolumn{2}{|c|}{ Coyote } & 1127 & 8998 & 15.87 & 22.58 & 11.50 & 83.82 \\
\hline \multicolumn{2}{|c|}{ Stine } & 969 & 8550 & 15.33 & 22.57 & 11.05 & 86.03 \\
\hline \multicolumn{2}{|c|}{ Giraf } & 1038 & 8333 & 16.33 & 21.88 & 10.72 & 87.50 \\
\hline \multicolumn{8}{|c|}{ Tohum tipi } \\
\hline \multirow{2}{*}{\multicolumn{2}{|c|}{$\begin{array}{c}\text { Kapsız } \\
\text { Kaplı }\end{array}$}} & 1031 & 8853 & $16.25^{\mathrm{a}}$ & 22.21 & 11.11 & 86.27 \\
\hline & & 1122 & 8693 & $15.59^{\mathrm{b}}$ & 23.39 & 11.33 & 85.54 \\
\hline \multicolumn{8}{|c|}{ Çeşit $\times$ tohum tipi } \\
\hline Eldorado & $\begin{array}{c}\text { Kapsız } \\
\text { Kaplı }\end{array}$ & $\begin{array}{c}968^{b} \\
1378^{a}\end{array}$ & $\begin{array}{c}8714^{\mathrm{abc} 12^{*}} \\
9706^{\mathrm{a} 1}\end{array}$ & $\begin{array}{c}17.24^{\mathrm{a}} \\
15.07^{\mathrm{cd}}\end{array}$ & $\begin{array}{l}22.53 \\
25.80\end{array}$ & $\begin{array}{l}11.37 \\
11.83\end{array}$ & $\begin{array}{l}86.27 \\
86.27\end{array}$ \\
\hline Coyote & $\begin{array}{c}\text { Kapsız } \\
\text { Kaplı }\end{array}$ & $\begin{array}{l}1142^{b} \\
1112^{b}\end{array}$ & $\begin{array}{l}8507^{\mathrm{bc} 12} \\
9489^{\mathrm{ab} 1}\end{array}$ & $\begin{array}{l}15.86^{\mathrm{bcd}} \\
15.87^{\mathrm{bcd}}\end{array}$ & $\begin{array}{l}22.70 \\
22.47\end{array}$ & $\begin{array}{l}11.30 \\
11.70\end{array}$ & $\begin{array}{l}83.33 \\
84.31\end{array}$ \\
\hline Stine & $\begin{array}{c}\text { Kapsız } \\
\text { Kaplı }\end{array}$ & $\begin{array}{c}931^{b} \\
1006^{b}\end{array}$ & $\begin{array}{l}8770^{\mathrm{abc} 12} \\
8331^{\mathrm{cd} 12}\end{array}$ & $\begin{array}{c}15.72^{\mathrm{bcd}} \\
14.93^{\mathrm{d}}\end{array}$ & $\begin{array}{l}22.07 \\
23.07\end{array}$ & $\begin{array}{l}10.97 \\
11.13\end{array}$ & $\begin{array}{l}86.27 \\
85.78\end{array}$ \\
\hline Giraf & $\begin{array}{c}\text { Kapsız } \\
\text { Kaplı }\end{array}$ & $\begin{array}{c}1084^{b} \\
992^{b}\end{array}$ & $\begin{array}{c}9421^{\mathrm{abc} 1} \\
7245^{\mathrm{d} 2}\end{array}$ & $\begin{array}{l}16.16^{\mathrm{abc}} \\
16.51^{\mathrm{ab}}\end{array}$ & $\begin{array}{l}21.53 \\
22.23 \\
\end{array}$ & $\begin{array}{l}10.80 \\
10.63 \\
\end{array}$ & $\begin{array}{l}89.22 \\
85.78 \\
\end{array}$ \\
\hline
\end{tabular}

*: Harfler \%5, rakamlar \%1 düzeyinde farklı grupları göstermektedir.

*: Letters and numbers stands for $\% 5$ and $\% 1$ levels of importance, respectively 


\section{Sonuç}

Sonuç olarak, beklenenin aksine, çeşitlerin çimlenme oranı, çıkış oranından daha düşük bulunmasına tohumların perikarp kısmında bulunan çimlenme engelleyici maddelerin kaynaklandığı söylenebilir. Eldorado ve Coyote çeşitlerinde kaplı tohumlar, Stine ve Giraf çeşidinde ise kapsız tohumlar daha yüksek verime sahip olmuşlardır. Giraf çeşidinde ise kaplı ve kapsız tohumlardan elde edilen verimler arasında önemli farklılıklar belirlenmiştir. Ancak bu farklıığa kaplı tohumlardan elde edilen $\% 4$ oranında daha düşük çıkış yüzdesinin neden olduğu düşünülmektedir. Sonuç olarak, çimlenme ve çıkış bakımından şeker pancarı çeşitlerinin kaplı ve kapsız tohumları arasında önemli farklıııklar belirlenirken, verim ve verim öğeleri ile polar şeker oranı bakımından belirgin bir üstünlük tespit edilmemiştir. Kaplı tohumların çimlenme ve çıkışının daha geç olması, verimde herhangi bir avantaja veya dezavantaja neden olmamışırı. Bu duruma şeker pancarı tarımının sulu koşullarda ve entansif şartlarda yapılması nedeniyle bitki gelişiminin ilerleyen dönemlerinde bu gecikmeyi telafi edebildiğini söylemek mümkündür. Bu nedenle çeşitlerin kaplı veya kapsız tohumlarının kullanılması açısından tohum maliyetleri ve ekim kolaylığı dikkate alınarak tercih yapılması gerektiği söylenebilir.

\section{Kaynaklar}

Anonim 2003. International rules for seed testing, Edition 2003, International Seed Testing Association, Zurich, Switzerland

Anonim 2015a. http://tuikapp.tuik.gov.tr/ bitkiselapp/bitkisel.zul (Erişim tarihi: 03.07.2015)

Anonim 2015b. http://www.tarim.gov.tr/BUGEM/ TTSM/Sayfalar/Detay.aspx?Sayfald=85 (Erişim tarihi: 03.07.2015)

Arıoğlu H.H., 2000. Nişasta ve Şeker Bitkileri. Ç.Ü.Z.F. Yayın no: 188. 234s

Battle J.P., Whittington W.J., 1969. The relation between inhibitory substances and variability in time to germination of sugar beet clusters. J.Agric. Sci., Camb., 73: 337-346

Duan X., Burris J.S., 1997. Film Coating Impairs Leaching of Germination Inhibitors in Sugar Beet Seed. Crop Science, 37(2): 515-520

Düzgüneş O., Kesici T., Kavuncu O., Gürbüz F., 1987. Araştırma ve Deneme Metotları (İstatistik Metodları II). A.Ü. Ziraat Fakültesi Yayınları:1021. Ders Kitabı, $295 \mathrm{~s}$

McQuilken M.P., Whipps J.M., Cooke R.C., 2007. Control of damping-off in cress and sugar beet by commercial seed coating with Phytium oligandrum. Plant Pathology, 39(3): 452-462

Taylor A.G., Allen P.S., Bennett M.A., Bradford K.J. Burris J.S., Misra M.K., 1998. Seed enhancements. Seed Science Research, 8(2): $245-256$ 